\title{
Contribuições submersas da Teoria das Elites aos Estudos Culturais Contemporâneos
}

\author{
Sandro Adalberto Colferai ${ }^{1}$
}

\section{Resumo}

$\mathrm{O}$ artigo explora as permanências do pensamento do sociólogo Vilfrido Pareto possíveis de ser apontadas no paradigma reconhecido como Estudos Culturais Contemporâneos, ECC. O argumento apresentado é de que nas formulações de António Gramsci para o conceito de Hegemonia são acionadas categorias propostas por Pareto na sua Teoria das Elites. Ainda que a ligação com os ECC não seja explícita, considera que parte dessas ideias se mantém entre pesquisadores e teóricos como Stuart Hall, Richard Johnson, Jesús Martín-Barbero e Néstor Garcia Canclini.

Palavras-chave: Estudos Culturais Contemporâneos; António Gramsci; Vilfrido Pareto; Teoria das Elites.

\section{Resumen}

El artículo explora las continuidades del pensamiento del sociólogo Vilfrido Pareto en el paradigma reconocido como Estudios Culturales Contemporáneos, ECC. El argumento es que en las formulaciones de Antonio Gramsci para el concepto de hegemonía son impulsadas categorías propuestas por Pareto en su Teoría de las Elites. Aunque el vínculo con el ECC no es explícita, considera que algunas de estas ideas se mantienen entre investigadores y teóricos como Stuart Hall, Richard Johnson, Jesús Martín-Barbero y Néstor García Canclini.

Palabras claves: Estudios Culturales Contemporáneos; Antonio Gramsci; Vilfrido Pareto; Teoría de las elites.

\begin{abstract}
The paper explores the continuities of thought Vilfrido Pareto sociologist possible to be pointed in the paradigm recognized as Contemporary Cultural Studies, ECC. The argument is that in Antonio Gramsci's formulations for the concept of hegemony proposed categories are driven by Pareto in his Theory of Elites. Although the link with the ECC is not explicit, considers that some of these ideas is maintained between researchers and theorists such as Stuart Hall, Richard Johnson, Jesús Martín-Barbero and Nestor Garcia Canclini.
\end{abstract}

Keywords: Contemporary Cultural Studies; Antonio Gramsci; Vilfrido Pareto; Theory of Elites.
${ }^{1}$ Doutor em Sociedade e Cultura (UFAM); mestre em Comunicação Social (PUCRS); professor de Jornalismo na Universidade Federal de Rondônia, UNIR, campus de Vilhena. Pesquisador do Mapa Cultural de Rondônia (UNIR-CNPq) e do Interfaces (UFAM-CNPq). 

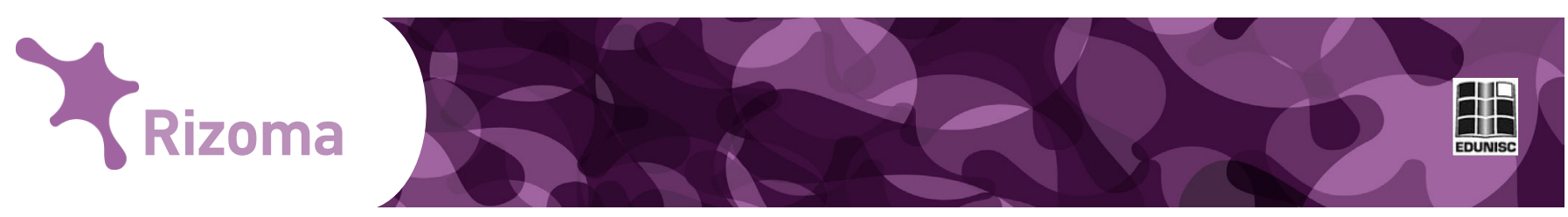

\section{O clássico submerso}

Os autores clássicos da sociologia têm lugar de destaque no pensamento social contemporâneo exatamente por serem clássicos e, para assim serem considerados, são várias as características e qualidades de suas obras que devem ser destacadas. Entre elas estão a capacidade de oferecer interpretações coerentes aos problemas das sociedade em que foram produzidas; sua presença e atualidade nas elaborações teóricas contemporâneas; e a possibilidade de, a partir delas, elaborar-se modelos que contribuam para compreender realidades sociais diferentes daquelas em que foram geradas (FREITAS, 2011a).

Ao considerar estas características dos clássicos da sociologia detenho a atenção nas contribuições da obra do sociólogo franco-italiano Vilfrido Pareto. É possível afirmar que seus escritos preenchem as condições expostas acima, mas que mesmo assim Pareto comumente não surge ao lado dos grandes clássicos da sociologia, e as apropriações de suas reflexões, na maior parte - é possível dizer - disseminadas entre alguns teóricos sociais contemporâneos, acontecem sem que haja menções diretas a Pareto.

Aqui, me concentro em um aspecto de sua obra, identificado de maneira geral como a Teoria das Elites, e nas leituras e interpretações que suscitou. Identifico intersecções entre as formulações propostas por Pareto presentes no paradigma dos Estudos Culturais, que têm proporcionado abordagens produtivas aos estudos em Comunicação nas décadas recentes. Ainda que seja possível indicar contribuições, a Teoria das Elites não surge de maneira direta nos Estudos Culturais, quer na sua vertente britânica ou latinoamericana. O que é possível apontar são elementos do pensamento de Pareto que chegam aos Estudos Culturais via escritos do italiano Antonio Gramsci.

Abordar tal presença é caminho sinuoso, ainda que a presença da Teoria das Elites na obra de Gramsci, em especial na sua conceituação de Hegemonia, seja fundamental para a construção teórica do paradigma dos Estudos Culturais Contemporâneos. O que acredito ser possível é identificar na leitura feita pelos teóricos dos Estudos Culturais uma compreensão da dinâmica social que, mesmo após o crivo de Gramsci, é muito próxima das percepções de Pareto.

\section{Os Estudos Culturais Contemporâneos}

Os Estudos Culturais não se constituem como uma linha de estudos homogênea. Antes disso, são a reunião de vertentes teóricas presentes em diferentes países, mas que têm semelhanças marcantes e que reconhecem uma trajetória comum. O campo é associado aos estudos em Comunicação, mesmo que haja uma clivagem particular centrada no reconhecimento das diferenças, na intervenção social, promoção da democracia e da igualdade nas relações. A gênese dos Estudos Culturais remete aos anos 1950, na Inglaterra, e é possível identificar nas obras de Richard Hoggart (The Uses of Literacy, 1957), Raymond Williams (Culture and Society, 1958) e Edward 

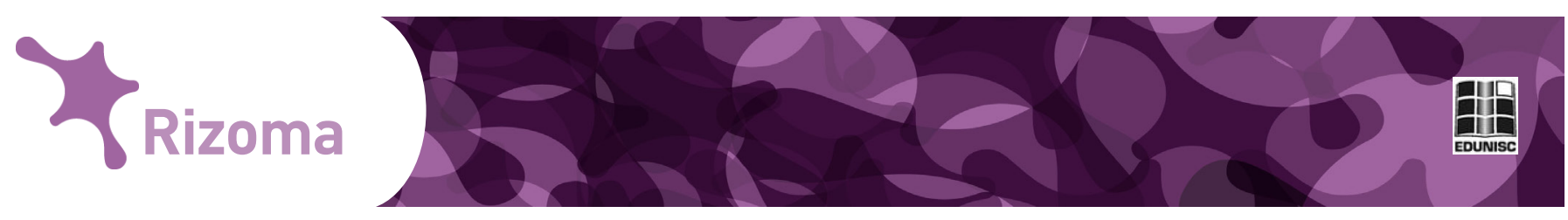

Palmer Thompson (The making of the English Working-class, 1963), as bases do novo paradigma. Nestes autores, e em suas obras e trajetórias pessoais, é possível apontar convergências que levam a novos posicionamentos e à crítica do "velho marxismo". As discussões que começaram na literatura chegaram a vertentes históricas e alcançaram a filosofia como "um racionalismo generalizado e uma atração por idéias abstratas" (JOHNSON, 2004, p. 12).

Da origem marxista às ultrapassagens já visíveis nos anos 1970, Johnson aponta três pontos de grande influência para a constituição dos Estudos Culturais: a íntima vinculação dos processos culturais com as relações sociais, em especial com as relações e formações de classes; o reconhecimento que cultura envolve poder e isso contribui para a produção de assimetrias na capacidade de indivíduos e grupos sociais em definirem e satisfazerem suas próprias necessidades; e a dedução de que a cultura não é um campo autônomo e nem externamente determinado, mas, ao invés disso, lugar de diferenças e lutas sociais. Para Johnson, estas premissas não esgotam os elementos do marxismo, porém dão espaço para que sejam criticados e estudados detalhadamente.

\begin{abstract}
De novo, para mim, muitos caminhos levam de volta a Marx, mas as apropriações precisam ser mais amplas. Tem havido, ultimamente, tentativas de se ir além da posição bastante estéril entre racionalismo e empirismo, em busca de uma formulação mais produtiva da relação entre teoria (ou "abstração", como eu prefiro, agora, dizer) e "estudos concretos”. (JOHNSON, 2004, p. 14).
\end{abstract}

As novas abordagens marxistas estão presentes nos Estudos Culturais nos textos de Raymond Williams, como é o caso de The Long Revolution, em que se posiciona contra a metáfora base/superestrutura, e coloca em seu lugar a interação mútua de todas as práticas como forma de contornar o problema da determinação. O que se busca nos estudos culturais é a totalidade social, ver o estudo da cultura como o estudo das relações na vida inteira (HALL, 2003[2006]a, p. 129).

É nesta direção que os Estudos Culturais alcançam as posições culturalistas, que criticam os processos sem sujeito do estruturalismo, mas tal aproximação se mostra suficiente para dar conta dos problemas que se impõem. Se por um lado o estruturalismo apresenta o determinismo, o culturalismo insiste na particularização das práticas, e tem como problema a retirada do olhar do todo. É neste encontro tenso, que também é complementar, que se desenvolve a agenda dos Estudos Culturais.

$\mathrm{Na}$ América Latina, percurso teórico-metodológico semelhante foi empreendido por diferentes pesquisadores, mesmo sem contato entre estes e aqueles da Inglaterra. Isso acontece a partir dos anos 1980 e se espalha pelo continente, e neste cenário se destacam os nomes de Jésus Martín-Barbero e Néstor Garcia Canclini. As percepções no contexto inglês da década de 1950 se mostram bastante semelhantes àquelas da América Latina dos 1970, principalmente com relação aos estágios do capitalismo e à inserção das indústrias culturais no cotidiano das populações (ESCOSTEGUY, 2001, p. 41). 

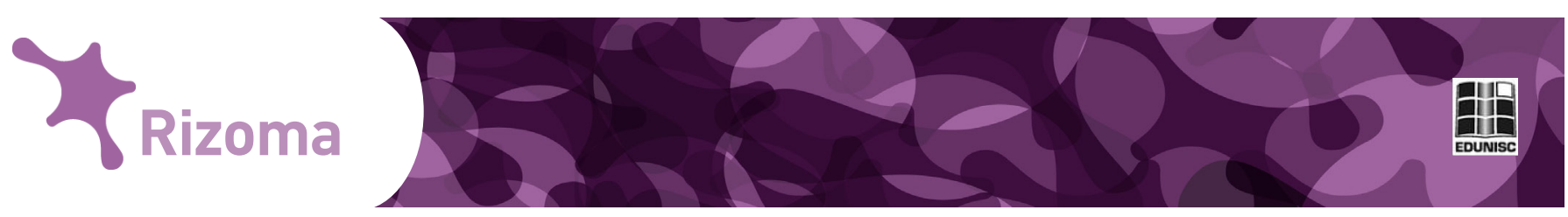

Entre as proposições de Martín-Barbero e Garcia Canclini está a fuga de análises reducionistas, tal como seriam as apresentadas pelo estruturalismo, e a busca por olhares transversais que possam superar barreiras disciplinares evitando dualismos teóricos. Eles propõem categorias analíticas como sincretismo, hibridação e mestiçagem, que não negam determinações estruturais, mas admitem a ação dos sujeitos no meio social. As identificações diretas com a perspectiva dos Estudos Culturais começam a acontecer somente nos anos 1990, todavia os percursos de ingleses e latinoamericanos são de tal modo semelhantes que pode-se conceber uma trajetória similar.

Embora nem o culturalismo nem o estruturalismo bastem, como paradigmas auto-suficientes para o estudo, eles são centrais para o campo, o que falta a todos os outros contendores, porque, entre si - em suas divergências assim como em suas convergências - eles enfocam o que deve ser o problema central dos Estudos Culturais. (HALL, 2003[2006] a, p. 147-148).

As aproximações nos Estudos Culturais entre estruturalismo e culturalismo, que representou a superação das posições marxistas ortodoxas, ou do "velho marxismo", como prefere Johnson (2004), se dá pela entrada de Gramsci, em especial o conceito de Hegemonia por ele desenvolvido, na discussão no ambiente inglês. A tomada de Gramsci também acontece na América Latina e significa a resposta para os problemas que vinham sendo colocados aos estudos da cultura, de forma semelhante, embora em momentos distintos, nos dois lados do Atlântico. Para Stuart Hall (2003[2006]a, p. 147), entre as diferentes vertentes dos Estudos Culturais aquela que partiu de conceitos elaborados por Antonio Gramsci e dos "melhores elementos" do culturalismo e do estruturalismo é a que mais se aproxima das exigências do campo.

\section{Os Estudos Culturais e Gramsci}

As percepções nos Estudos Culturais, tanto na Inglaterra como na América Latina, da necessidade de superar as dualidades passou pelo entendimento de que não era possível intercambiar cultura e ideologia, esta uma categoria althusseriana. Cultura neste paradigma tem vasta abrangência, indo além das representações sociais postas, alcançando reelaborações das estruturas sociais e abrindo espaços para imaginar novas proposições. Ideologia, por outro lado, é vista como deformação, reflexo e representação das condições reais de existência.

Outro ponto de divergência foi a ideologia tomada desde posições marxistas, sempre privilegiando interesses de classes, em última instância interesses determinados pelo econômico. Este é o motivo pelo qual nos Estudos Culturais há a preferência pelo termo cultura, ao invés de ideologia. Mas, mesmo com esta posição consolidada era fundamental um aporte teórico capaz de considerar as dinâmicas sociais de forma descentrada do econômico, e colocar, na mesma arena, outros elementos das relações 

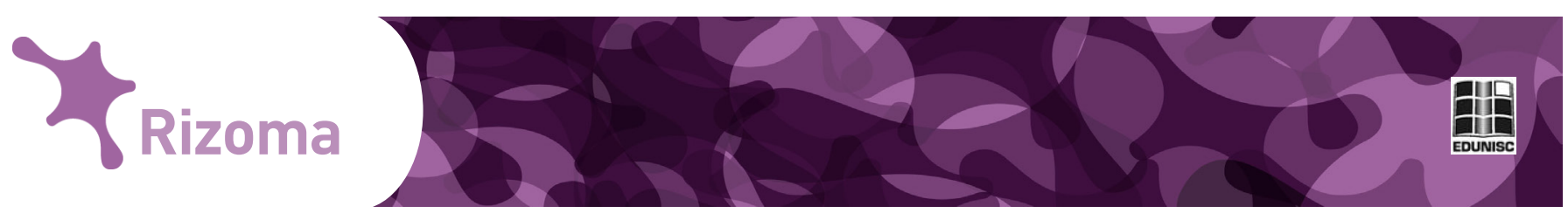

sociais. A introdução do conceito de Hegemonia nos Estudos Culturais foi fundamental desde a proposta de Raymond Williams, como maneira de "deslocar a idéia de cultura do âmbito da ideologia, isto é, da reprodução social” (ESCOSTEGUY, 2001, p. 95).

Este é o caminho que percorrem Hall, na Inglaterra, e Martín-Barbero e Garcia Canclini na América Latina, que por caminhos distintos acabam chegando a Antonio Gramsci e ao seu conceito de Hegemonia.

Diante da perspectiva que desembocava invariavelmente em reprodução
social, a incorporação, sobretudo, do conceito de hegemonia de Antonio
Gramsci permitiu vislumbrar um movimento mais dinâmico e complexo
na sociedade, admitindo tanto a reprodução do sistema de dominação
quanto a resistência a esse mesmo sistema. Em termos genéricos,
esse argumento é válido para a vertente britânica, assim como para a
perspectiva latino-americana. (ESCOSTEGUY, 2001, p. 91).

A incorporação de uma parte das reflexões de Gramsci no contexto dos Estudos Culturais britânicos se deu principalmente sob a liderança de Stuart Hall, que fez ataques contundentes ao reducionismo e economicismo do marxismo clássico. "Essa abordagem tende a ver todas as outras dimensões da formação como simples espelho do 'econômico' em outro nível de articulação e não tendo nenhuma força determinante ou estruturadora no seu próprio direito" (HALL, 2003[2006]b, p. 285).

Para Escosteguy (2001) na América Latina o aporte gramsciano circunscreve-se nas "análises propriamente culturais" e com forte conotação política principalmente por dar vazão ao popular, antes desconsiderado nas análises empreendidas. E isso se dá, principalmente, pelo conceito de Hegemonia, que desde o âmbito do popular repercute na análise cultural da comunicação. Martín-Barbero reconhece a importância de Gramsci na análise cultural por desbloquear "[...] o debate sobre a cultura dentro do marxismo e contribuindo de forma fundamental à construção de sua própria proposta investigativa da comunicação" (ESCOSTEGUY, 2001, p. 92).

Desta forma o aporte da Hegemonia de Gramsci aparece nos Estudos Culturais como ponto fundamental para avançar na discussão do cultural, agora livre das limitações estruturais, por um lado, e das indefinições culturalistas, por outro. Esta ultrapassagem, ancorada em Gramsci, vai permitir o entendimento de contextos históricos e de formações sociais como ativamente produzidas por indivíduos e por grupos sociais, mas ainda assim mantendo, mesmo que de maneira não contundente, a tensão entre as estruturas e os sujeitos.

A estrutura dinâmica de análise histórica permite ao pensamento de Gramsci, e aos Estudos Culturais, voltar-se às relações de força no terreno concreto da luta e do desenvolvimento político e social. E nesta relação de forças não há totalidades, vitória de um lado ou outro ou mesmo a total incorporação. O que há é uma questão relacional, um equilíbrio instável em um processo contínuo de formação e superação. Hall destaca que a idéia de vitória total da burguesia sobre as classes trabalhadoras ou "[...] a total 

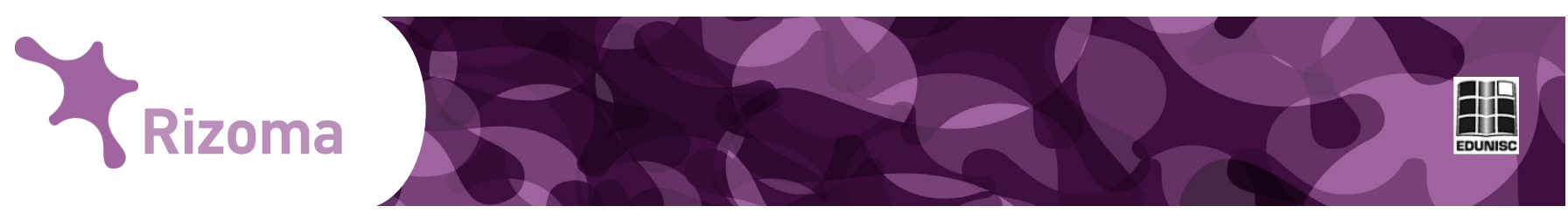

incorporação da classe trabalhadora ao projeto burguês é totalmente estranha à definição de hegemonia de Gramsci" (2003[2006]b, p. 292).

Para Hall, ao invés da vitória, Gramsci observa diferentes estágios em que consciência, organização e unidade de classe podem se desenvolver. O último deles, o momento da hegemonia, vai além da solidariedade econômica pura e alcança os interesses dos grupos subordinados e se propaga pela sociedade, "[...] promovendo a unidade intelectual, moral, econômica e política [...]" (HALL, 2003[2006]b, p. 293), propõe as questões em torno das quais as lutas acontecem e cria a hegemonia do grupo social principal sobre os vários grupos subordinados.

\section{Hegemonia e Teoria das Elites}

Temos claro que as contribuições de Gramsci são originais e surgem no ambiente político e intelectual da Itália das primeiras décadas do século $\mathrm{XX}$, terreno extremamente fértil para um pensamento social pertinente à época e que perdura até a contemporaneidade. É neste mesmo contexto que a principal obra de Pareto, o Traité de Sociologie Générale, de 1917, portanto anterior aos principais escritos de Gramsci, surge como influência importante. Além disso, é possível afirmar que Antonio Gramsci foi leitor e crítico da obra de Vilfrido Pareto e o pensamento deste teve papel importante na formação do conceito de Hegemonia, assim como nas idéias acerca da questão política dos intelectuais.

Gramsci explicita a sua maneira de trabalhar em uma carta à cunhada Tatiana Schucht, em 1930, nela esclarece o quanto seria difícil para ele pensar de maneira desinteressada: "Comumente é necessário colocar-me desde um ponto de vista dialógico ou dialético, caso contrário não sinto nenhum estímulo intelectual" (GRAMSCI apud ALIAGA, 2009, p. 6). Assim estabelece profícuo diálogo com a obra de diversos pensadores, mesmo que não haja abundantes referências a eles em seus escritos.

As referências diretas à Teoria das Elites nos Cadernos do Cárcere são raras e uma leitura pouco atenta pode mesmo tomar a sua importância como secundária, entretanto “[...] estas referências possuem notável agudeza crítica, envolvendo algumas das temáticas fundamentais da teoria política enfrentada por Gramsci no cárcere" (ALIAGA, 2009, p. 3).

Em uma das poucas referências diretas a Pareto nos Cadernos do Cárcere, Gramsci diz que a Teoria das Elites é,

\footnotetext{
“[...] uma tentativa de interpretar o fenômeno histórico dos intelectuais e a sua função na vida estatal e social [...]", e uma forma de esclarecer o processo pelo qual lideranças de classes subalternas acabam por defender as estruturas vigentes, enquanto se mantêm como dirigentes de "[...] um grupo subalterno, que não conquistou ainda a consciência de sua força e das suas possibilidades e modos de desenvolvimento" (GRAMSCI apud SCHLESENER, 2007, p. 5).
}

Enquanto, na Teoria das Elites é possível estabelecer as tomadas de 

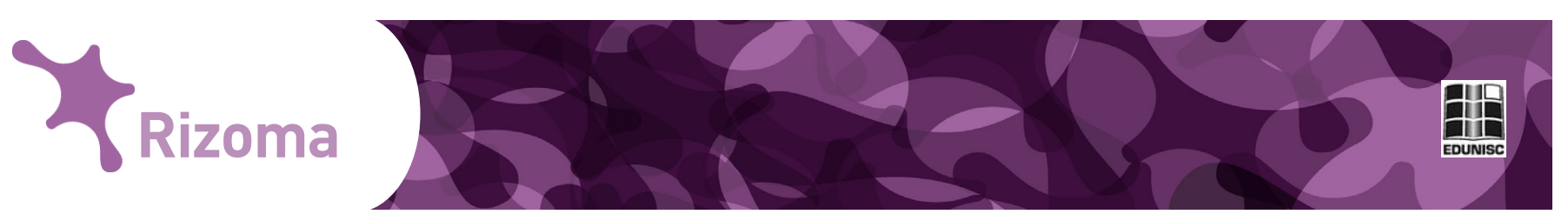

decisão do homem a partir dos resíduos e derivações, Gramsci enxerga aí a fase de primitivismo nas relações entre as classes que deve ser superada.

As aproximações possíveis entre a Teoria das Elites e o conceito de Hegemonia - este também disperso nos escritos grasmcianos - são constantes, assim como os tensionamentos. Estes últimos podem ser compreendidos mais pelo posicionamento ideológico de Gramsci, que opera a partir de categorias marxistas, do que por divergências na leitura feita por ele e Pareto do contexto imediato que analisam. Assim que se aproximam aquilo que é apresentado como a circulação das elites por Pareto, e para Gramsci "questão política dos intelectuais".

Pareto aponta a circulação das elites como um dos fatores que faz com que a sociedade se caracterize pela mútua dependência dos elementos que a compõem. Estes elementos são situados em um ambiente variável, ecológico, internacional e histórico. Ao lado da circulação das elites coloca as derivações, resíduos e os interesses como outros fatores determinantes para as relações sociais. Como se trata de fatores variáveis, as sociedades também são diferentes entre si.

Os grupos sociais, em Pareto - sejam eles quais forem - têm suas elites, e entre os membros dessas diversas elites se destacam determinados indivíduos. Tais indivíduos não são, necessariamente, os mesmos que compõem a elite dirigente, havendo, assim, uma elite não-governamental e uma elite governamental.

\footnotetext{
Em sentido amplo a elite é definida fora de toda consideração moral; a circulação das elites é a mobilidade social que afeta em toda a sociedade o grupo social dirigente. Toda sociedade é caracterizada pela natureza social de sua elite governamental que se impôs como dirigente à camada inferior, seja pela força, seja pela astúcia, pois toda elite política seja ela leoa ou raposa, luta pela vida. (FREITAS, 2011b, p. 4-5).
}

Gramsci destaca a existência de intelectuais em todas as classes sociais, e que estes seriam os responsáveis pela sua condução. Na elaboração do conceito de Hegemonia Gramsci aponta que o dirigente de Estado e de Governo está relacionado às classes sociais. Primeiro, lança a ideia como questão, perguntando se os intelectuais são um grupo autônomo ou se cada grupo tem seus próprios intelectuais, para em seguida responder:

Todo grupo social, nascendo sobre terreno originário de uma função essencial no mundo da produção econômica, cria para si, ao mesmo tempo, organicamente, uma ou mais camadas de intelectuais que lhe dão homogeneidade e consciência da própria função, no campo econômico. (GRAMSCI apud ALIAGA, 2009, p. 5).

Cada classe social, portanto, cria seus próprios intelectuais que, diferentes dos intelectuais tradicionais, que têm atitude regressiva, teriam ação progressiva ligada às necessidades econômicas, políticas e éticas. É fundamental apontar, neste ponto, que para Gramsci a idéia de intelectual 
vai além de uma visão tradicional, elitista, e desta forma todas as camadas sociais têm intelectuais, que devem assumir o papel de esclarecer e conduzir as classes a que pertencem na luta com as classes dominantes. A elite de intelectuais é definida não em contraste com a massa, mas na ligação orgânica com a classe a que pertence, e tem função diretiva e organizativa, com o objetivo de criar novos estratos intelectuais vindos das classes populares. É assim que uma parte da massa, mesmo que subalterna, é dirigente e responsável (ALIAGA, 2009, p. 10). Esta dinâmica pressupõe sempre o antagonismo entre a classe dominante e as classes subalternas.

Para Pareto os conflitos sociais surgem em todas as camadas sociais e entre os mais diferentes grupos, e não apenas entre as classes definidas na relação entre capital e trabalho, ou entre dominantes e dominados. Pareto apresenta como não estáticos os grupos sociais e as elites de cada um deles. "É a circulação das elites que move a história particular das sociedades pela mudança que provoca, e não a luta de classes" (FREITAS, 2011b, p. 5). A circulação é o movimento pelo qual espaços são abertos para que indivíduos que constituem a elite de um grupo ascendam a outros grupos, e assim mantenham a aparente unidade social.

A importância da circulação das elites, necessária à evolução histórica, se dá pelos novos valores, comportamento econômicos e sociais e pelo novo dinamismo coletivo que daí resulta, o que leva a processos de mobilidade social que equilibram a alternância do poder nas sociedades hierarquizadas. Gramsci admite esta circulação, mas a toma como um problema a ser superado para o fortalecimento da sociedade civil. Trata a circulação como cooptação de lideranças populares e denomina "transformismo" a retirada às classes trabalhadoras das condições de emancipação política (SCHLESENER, 2007, p. 4).

Fundamental apontar que na circulação das elites os movimentos sociais dela advindos independem dos sistemas sociais - capitalismo, socialismo, feudalismo. Pareto trata, primordialmente, das características que considera intrínsecas aos homens em sociedade. Daí que as condições para a circulação das elites são dadas desde os interesses, e estes surgem das derivações e resíduos. "Os interesses são o conjunto de tendências, instintivas e racionais que impulsionam os indivíduos e coletividades "a se apropriar dos bens materiais úteis, ou somente agradáveis para a vida assim como procurar a consideração e honra" (PARETO apud FREITAS, 2011b, p. 4).

Os resíduos, conceito fundamental para a teoria paretiana, são as razões últimas dos seres humanos, as motivações despidas de toda a racionalidade, os motivos que, de fato, levam às ações individuais e/ou coletivas. Pareto os divide em seis classes: instinto das combinações; persistência dos agregados; necessidade de manifestar os sentimentos por meio de atos exteriores; resíduos relacionados com a sociabilidade; integridade dos indivíduos e dos seus dependentes; e os resíduos sexuais. Estas classes, por sua vez, foram por ele subdivididas em gêneros.

Para justificar e dar a aparência racional aos resíduos o homem cria narrativas que dão conta das atitudes tomadas. É o que Pareto chama de 
derivações, que variam de acordo com o contexto social, histórico e mesmo as condições do ambiente.

As derivações são os elementos variáveis do conjunto constituído pela conduta humana e seu acompanhamento verbal. Representam, na linguagem de Pareto, o equivalente do que chamamos normalmente de ideologia, ou teoria justificativa. São os diferentes meios de ordem verbal, pelos quais os indivíduos e os grupos dão uma lógica aparente ao que, na verdade, não tem lógica, ou nem tanto quanto os atores gostariam de fazer crer. (ARON, 2008, p. 640-641).

A teoria paretiana faz a leitura das relações sociais a partir da natureza humana, o que fica evidente ao olhar atento acerca dos resíduos e derivações. Enquanto, a primeira categoria trata das motivações humanas, em que devem ser elencados os gostos e vontades pessoais, e mesmo as vaidades e egoísmos, cabe à segunda categoria criar as narrativas que dão a aparência racional às motivações, seja através dos mitos ou novas organizações sociais.

Gramsci constrói seu pensamento desde bases racionais, que para Pareto não são possíveis de ser consideradas de maneira exclusiva. Para Gramsci é preciso haver o debate exaustivo e transparente para levar adiante o projeto de uma democracia socialista, o que implica na expressão do pensamento livre e aberto, que neste contexto:

não se caracteriza pela autonomia do pensamento individual, mas pela elaboração de uma concepção de mundo coletiva e continuamente reformulada pela política. É esta prática que gera condições para o grupo social decidir sobre seu próprio destino e contribuir para a gestação de uma nova sociabilidade. (SCHLESENER, 2007, p. 3).

Pareto, por seu turno, é pessimista com as chances de poder haver democracia e, especialmente, de se conseguir chegar a algum grau de socialismo autêntico. Aquilo que para Gramsci é ponto crucial para uma nova sociabilidade, a percepção lógica para uma nova constituição social desde o debate exaustivo e transparente, é em Pareto razão de crítica, pois seria motivado por uma crença, sendo assim não-lógico, logo um resíduo e gerador de derivações. $\mathrm{O}$ argumento de Pareto é exemplificado por revolucionários que lutam para mudar um sistema social que lhes parece opressivo. A finalidade é implantar um sistema de liberdade, mas ao tomarem o poder acabam por instaurar um sistema opressor com consequência imprevisíveis (FREITAS, 2011b, p. 4) $)^{2}$.

Para além dos tensionamentos há as convergências e, principalmente, o que parecem ser contribuições tomadas por Gramsci da obra de Pareto. É certo que tal inferência deve ser tomada desde as elaborações de Gramsci que, como destacado, ofereceu uma reflexão original que parte da leitura crítica daqueles que o precederam. Assim, é possível ver no conceito de Hegemonia de Gramsci a estrutura social apresentada por Pareto em sua Teoria das Elites, mas revista a partir de uma leitura dialética-materialista.
${ }^{2}$ Aqui vale a questão levantada por Rêgo, para quem Gramsci poderia estar superestimando a figura do homem como "bom selvagem" rousseauniano, ao invés de uma visão mais realista do "homem como lobo do homem" hobbesiano: "Não seria o Estado-ético apenas conseqüência da projeção desse tipo ideal de homem? e portanto uma sociedade capaz de ser viável apenas na hipótese remota de ser composta por anjos e não por homens?" (RÊGO,

1991, s/p). 

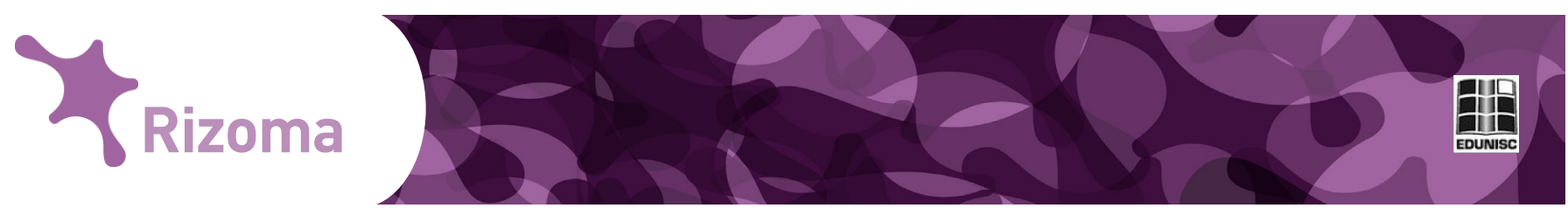

\section{Pareto nos Estudos Culturais}

A apropriação do conceito de Hegemonia pelos Estudos Culturais representou para este paradigma a possibilidade de ultrapassar as leituras dualistas e economicistas das relações sociais. Ao deter-se sobre as leituras feitas nos Estudos Culturais, tanto na vertente britânica como latinoamericana, surge não somente o relevo que o pensamento de Gramsci ganhou, mas o quanto as percepções a partir dele levadas a efeito se aproximam das idéias presentes na Teoria da Elites tal como concebidas por Pareto.

Ao buscar maneiras de superar o determinismo do econômico sobre as relações sociais, tal como proposto pelo marxismo clássico, os Estudos Culturais buscam alternativas, encontradas em Gramsci. E a clivagem a que submetem seus conceitos torna possível enxergar as estruturas e relações elitistas. Hall (2003[2006]c, p. 273) argumenta que entre os problemas do econômico está a incapacidade de assegurar a correspondência e fornecer modos de raciocínio a classes específicas. Isso ocorre por que categorias ideológicas são desenvolvidas, geradas e transformadas de acordo com leis próprias, apesar de serem geradas a partir de materiais específicos. Outra razão é o que Hall considera a necessária abertura do desenvolvimento histórico à prática e luta, o que leva à necessidade de reconhecer a realidade indeterminada do político.

Neste sentido a apreensão buscada pelos Estudos Culturaisé poruma abordagem que privilegie uma indeterminação relativa, que seja científica ao mesmo tempo em que considere elementos que não são necessariamente científicos:

É científica porque compreende a si mesma como determinada e por que busca desenvolver uma prática teoricamente informada. Mas não é científica no sentido de que os resultados políticos e as conseqüências da condução das lutas políticas estejam escritos nas estrelas econômicas. (HALL, 2003[2006]c, p. 273).

Neste posicionamento, que nos Estudos Culturais encontrou ancoragem no pensamento gramsciano, é possível identificar a estrutura social pensada na Teoria das Elites, em especial as indeterminações que são consideradas desde os resíduos e tomam corpo racional nas derivações. Trata-se da apreensão de Pareto de que os indivíduos reunidos em sociedade agem por motivações não racionais, mas dão corpo racional às narrativas que constroem. Os Estudos Culturais não assumem esta irracionalidade como base, mas o paradigma busca a indeterminação ancorada no material para construir as bases de sua leitura do social.

Da mesma maneira ao se apropriarem da formulação de Gramsci sobre os intelectuais é possível enxergar as elites - para Pareto - constituídas nos diferentes grupos sociais e sobre a sociedade como um tudo. Hall ao abordar as disputas entre classes tal como expostas por Gramsci, retoma a necessidade do proletariado se tornar dirigente através de um "sistema de alianças", o que acaba por colocar “[...] na agenda certas questões estratégicas críticas, como as convenções nas quais uma classe como a camponesa poderia vencer uma luta nacional não pela coerção, mas pela "conquista do consentimento"' (HALL, 2003[2006]b, p. 295).

Podemos, aqui, retomar a formulação de Pareto, para quem os meios de 

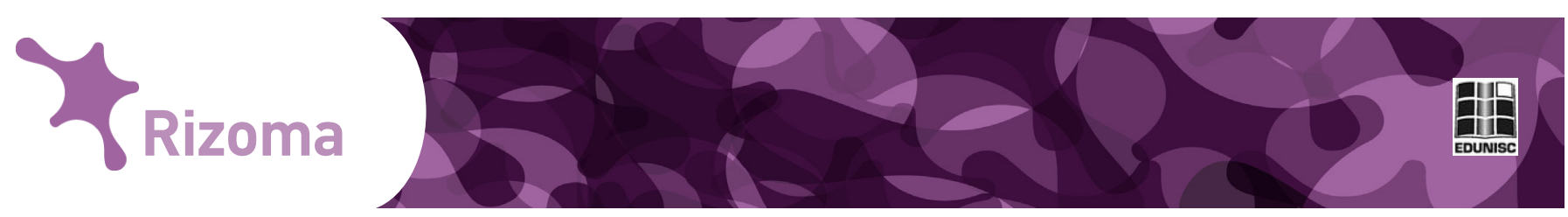

governo, e de acesso a ele, pode se dar pela força ou a astúcia, ou seja, a transposição da oposição entre leões e as raposas, uma categorização paretiana pertinente tanto a indivíduos como a grupos sociais. A analogia entre as ações políticas dos seres humanos e duas raças animais faz se aproximarem decisões, tomadas no âmbito social, e desejos e impulsos não racionais.

$\mathrm{Na}$ América Latina Martín-Barbero e Garcia Canclini realizam leituras da Hegemonia de Gramsci - e de aspectos importantes de sua obra para este conceito - que também se aproximam das contribuições de Pareto, em especial da Teoria das Elites. No ambiente latinoamericano, especialmente, é preciso salientar que a agenda principal é pensar a comunicação a partir da cultura, e neste sentido ganha relevo a idéia de fugir do reducionismo do materialismo mecanicista e buscar as indeterminações nas relações sócioculturais. Por esta abordagem o termo cultura significará

“[...] a produção de fenômenos que contribuem, mediante a representação ou reelaboração simbólica das estruturas materiais, para compreensão, reprodução ou transformação do sistema social, ou seja, a cultura diz respeito a todas as práticas e instituições dedicadas à administração, renovação e reestruturação do sentido" (GARCIA CANCLINI apud ESCOSTEGUY, 2001, p. 94).

A ênfase dada, no contexto latinoamericano assim como no britânico, às determinações estruturais tanto quanto a indeterminações individuais, não obscurece a presença da estrutura social proposta por Pareto, em que as elites de grupos e as elites dirigentes da sociedade têm papel fundamental. A leitura de Gramsci, depois assumida pelos Estudos Culturais, as mantém, mesmo que sob os olhares de um marxismo que, apesar de renegar o ortodoxismo materialista, dirige os olhares para outros lugares que não aqueles para onde olhava Pareto.

Os diferentes contextos, seja o das primeiras décadas do século XX na Itália e da emergência de regimes socialistas, ou do final do século e início do XXI, não fazem desaparecer as formas de organização social, e as motivações humanas fundamentais para entendê-las. As vontades, os desejos e paixões ainda são pontos fundamentais para compreender as dinâmicas sociais, mesmo que submergidos diante de exigências de racionalidade científica. É neste ponto que a sociologia de Pareto pode ser vista nas formulações contemporâneas que fogem de determinismos, esta uma atitude reivindicada pelos Estudos Culturais.

\section{Referências}

ALIAGA, Luciana. A “questão política dos intelectuais": um diálogo crítico de A. Gramsci com a Teoria das Elites. Anais do VI Colóquio Internacional Marx e Engels. Campinas, 2009. Disponível em http://www.ifch.unicamp.br/ cemarx/coloquio/Docs/gt2/Mesa2/a-questao-politica-dos-intelectuais--umdialogo-critic.pdf. Acesso em 02/08/2011.

ARON, Raymond. As etapas do pensamento sociológico. Trad. Sérgio Bath. $7^{\mathrm{a}}$ ed. São Paulo: Martins Fontes, 2008. 

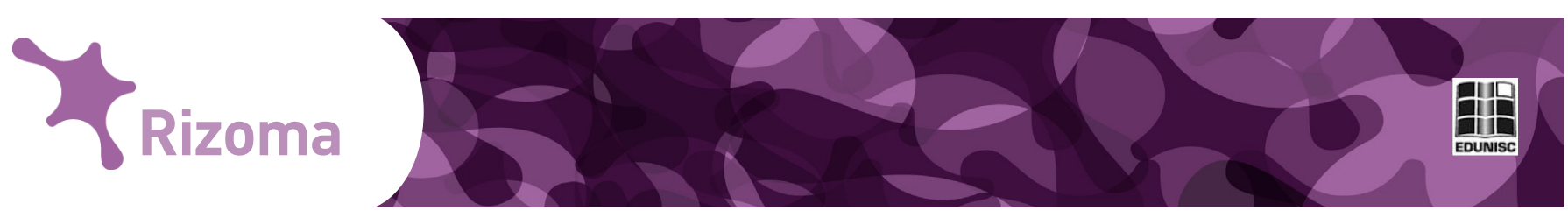

BIANCHI, Álvaro, ALIAGA, Luciana. Força e consenso como fundamentos do estado: Pareto e Gramsci. Revista Brasileira de Ciência Política. Brasília, n. 5, jan.-jun. 2011. Disponível em: http://www.rbcp.unb.br/artigo_html. php?id=71. Acesso em 02/08/2011.

ESCOSTEGUY, Ana Carolina. Cartografias dos Estudos Culturais - Uma versão latino-americana. Belo Horizonte: Autêntica, 2001.

FREITAS, Marilene Corrêa da Silva. Pareto e a questão social: elementos para uma discussão acerca dos sistema de solidariedade. Manaus, 2011. Relatório de pós-doutorado. Inédito.

. Visão geral da sociologia de Pareto. Manaus, 2011. Relatório de pós-doutorado. Inédito.

JOHNSON, Richard. O queé, afinal, Estudos Culturais. In: O que é, afinal, Estudos Culturais. Trad. Tomaz Tadeu da Silva. $3^{\mathrm{a}}$ ed. Belo Horizonte: Autêntica, 2004.

HALL, Stuart. Estudos Culturais, dois paradigmas. In: Hall, Stuart. Da Diáspora-Identidades e mediações culturais. Liv Sovik, org. Trad. Adelaide La Guardia Resende...[et alli]. Belo Horizonte: UFMG, 2003[2006].

. A relevância de Gramsci para o estudo de raça e etnicidade. In: Hall, Stuart. Da Diáspora-Identidades e mediações culturais. Liv Sovik, org. Trad. Adelaide La Guardia Resende...[et alli]. Belo Horizonte: UFMG, 2003[2006].

. O problema da ideologia, o marxismo sem garantias. In: Hall, Stuart. $D a$ Diáspora - Identidades e mediações culturais. Liv Sovik, org. Trad. Adelaide La Guardia Resende...[et alli]. Belo Horizonte: UFMG, 2003[2006]c.

MARCONDES FILHO, Ciro. De repente o prédio falou comigo. Anotações sobre experiência metapóricas em Teoria da Comunicação. In: 2011 - XX Compós: Porto Alegre/RS. GT Epistemologia da comunicação. Em: www.compos.org.br.

RÊGO, João. Reflexões sobre A Teoria Ampliada do Estado em Gramsci. Jornal do Commercio, Recife, 5 abr. 1991. Disponível em http://www. fundaj.gov.br/docs/inpso/cpoli/JRego/TextosCPolitica/Artigos/Gramsci/ gramsci.htm. acesso em 02/08/2011.

SCHLESENER, Anita. A crítica de Gramsci à Teoria das Elites: Pareto, Mosca e Michels e a democracia burguesa. Anais do VColóquio Internacional Marx e Engels. Campinas, 2007. Disponível em http://www.unicamp.br/ cemarx/anais_v_coloquio_arquivos/arquivos/comunicacoes/gt1/sessao4/ Anita_Schlesener.pdf. Acesso em 02/08/2011. 